\title{
Turn up the heat
}

\author{
Mounting calls for action on low-carbon heating and cooling systems are welcome, but we must move beyond only \\ talking about it.
}

$\int$ epending on where you are, heating and cooling can represent between 30 and $50 \%$ of total energy use, alongside electricity and transportation. Yet you would be hard-pressed to say that it represented between 30 and $50 \%$ of the energy discussion. This is unfortunate to say the least, as we cannot meet our climate change goals by mid-century or the end of the century without serious changes to our heating and cooling systems. In some ways it's easy to see why decarbonization of this sector hasn't been tackled as fervently as electricity and transport: aside from being arguably far more complex than the others, it's hard for many of us to get as excited about boilers, air conditioners and building insulation as it is about solar panels or electric vehicles. Hopefully that's all set to change in the next few years.

Helping spur fresh excitement, a new report from the UK's Committee on Climate Change (CCC $)^{1}$ proclaims that hydrogen is a viable route to decarbonizing the UK's energy system, highlighting a number of important uses in heating systems. Nature Energy has long been a champion of research on hydrogen production, so this news will no doubt be cause for celebration among many of our authors and readers. However, the CCC notes that hydrogen isn't a silver bullet and that there are still impracticalities and obstacles preventing it from completely replacing existing energy options in a net-zero carbon system. Instead, hydrogen offers many benefits when used alongside electrification. This reinforces the increasingly recognized need to think about electricity and heating and cooling as integrated systems that can deliver substantive co-benefits.

There are many research challenges and opportunities presented by this picture. Developing technologies to generate low-carbon hydrogen is just one of them. The pages of Nature Energy and many other journals are filled with suggestions, yet the viability of hydrogen hinges not just on being low-carbon, of course; it has to be produced at competitive prices and at scale.
Research is going to have to tackle these two aspects in earnest, in terms of materials science and technology, and economics and market models. An improved understanding of how to scale up demonstration projects and plants will be critical. Beyond the lab bench, trials of hydrogen for public transit, power generation, or in gas supplies are nothing new, but their offer of controllable scenarios without major structural change presents ideal test beds for new technologies or markets in the real world that may reap tangible benefits if further supported. In this regard, recent support from the $\mathrm{EU}^{2}$ and funds like the UK’s $£ 20$ million Hydrogen Supply Program ${ }^{3}$ are welcome.

Heat is presented with major challenges besides the role of hydrogen, of course. Public engagement with and understanding of heat decarbonization is low, as is understanding and acceptance of lowcarbon heating technologies like air- or ground-source heat pumps or heat networks. Historical lock-in means that most people are used to a particular way of regulating the temperature of their homes and are often reluctant to change it for something new. At the same time, how individuals think about and use heating and cooling technologies varies enormously.

These are critical barriers to the deployment of solutions. Research is urgently needed to understand end users and their needs, as well as their technology adoption behaviours. We then have to understand how to integrate these findings with system models and new technologies or business models, to build an accurate picture of what may work in practice. Initiatives like the Energy Systems Catapult's Home Energy Services Gateway (https://go.nature.com/2Q1U8n3) could offer useful insights here.

Let's also recognize that heating and cooling are ways of achieving personal comfort, not just ends in themselves. For example, a reduction of ventilation intended to reduce energy consumption of a boiler can lead to air quality problems with potentially serious health impacts. A fixation on home heat efficiency risks unforeseen consequences elsewhere.

Digitalization can play a big role here. At the household level, the growth of smart home systems offers a wealth of data on consumption and practice. These systems also enable more-integrated thinking about power and heat, and provide greater degrees of user control and engagement - all desirable outcomes for the energy transition if appropriately managed.

Heating and cooling also face the everpresent question of costs. Any change to decarbonize thermal regulation systems is going to be expensive. Aside from changes to infrastructure and appliances, building retrofits have long been a thorny problem and the jury is still out on the effectiveness of many energy efficiency programs. Policy is going to be important here, along with development of new business models, to incentivize change and drive down costs. More comprehensive evidence on what works will be vital to these efforts.

These costs also bring questions of equity. How do we build a low-carbon heat system that is fair and doesn't leave some parts of society behind? Fuel poverty and energy justice research has a pivotal role, as we start looking at deployment options, and deserves greater attention.

The transition to a decarbonized heat system is not going to be an easy one but it is certainly achievable. The energy research community has an enormous amount to offer to all aspects of this challenge. In the end, though, it is going to take more substantive action from governments - at all levels - to create meaningful change and build enabling environments.

Published online: 10 December 2018 https://doi.org/10.1038/s41560-018-0305-y

References

1. Hydrogen in a Low-carbon Economy (CCC, 2018); https://go.nature.com/2BzNkKb

2. Psaledakis, D. EU countries agree to explore hydrogen as energy source. Reuters (18 September 2018); https://go.nature. $\mathrm{com} / 2 \mathrm{E} 1673 \mathrm{H}$

3. Shrestha, P. Details of $£ 20$ m hydrogen supply competition published. Energy Live News (20 November 2018); https://go.nature.com/2zpXXhi 